DOI: https://doi.org/10.47405/mjssh.v6i10.1079

\begin{tabular}{|c|c|}
\hline 4.581 & Malaysian Journal of Social Sciences and Humanities (MJSSH) \\
\hline $\begin{array}{l}\text { Malaysian Journal of } \\
\text { Social cciences and }\end{array}$ & Volume 6, Issue 10, October 2021 \\
\hline (MJ-SSH) & e-ISSN : 2504-8562 \\
\hline & $\begin{array}{l}\text { Journal home page: } \\
\text { www.msocialsciences.com }\end{array}$ \\
\hline
\end{tabular}

\title{
Governing the Risks of Cyber Bullying in the Workplace During the Era of Covid-19
}

\author{
Wan Rosalili Wan Rosli', Syazni Nadzirah Ya'cob' ${ }^{1}$, Mimi Sintia Mohd Bajury¹, \\ Mardiyah Hayati Abu Bakar'1 \\ 1Faculty of Law, Universiti Teknologi MARA, 404050,Shah Alam, Selangor, Malaysia \\ Correspondence: Wan Rosalili Wan Rosli (rosalili@uitm.edu.my)
}

\begin{abstract}
With the advancement of ICT, cyberbullying has become more common than ever before, particularly in modern workplaces. With the requirement of working from home during the pandemic, cyberbullying within the workplace has skyrocketed within the past year. Cyberbullying can be classified as a traditional crime that has transcended to cyberspace as a result of technological advancements and the proliferation of numerous social media platforms. Despite widespread public concern about such crime in Malaysia, the legislative response to this crime is still somewhat slow due to the gaps in the current legislation governing cyberbullying. The legal landscape governing cyberbullying is still insufficient, due to the current legal framework being too general, making investigation and prosecution of the crime difficult. Cyberbullying can result in Post-Traumatic Stress Disorder, psychological problems, major physical and mental health problems, and even suicide. The purpose of this article is to investigate the notions of cyber bullying harassment, the risks associated with such crimes, and the legal and management mechanisms for dealing with such crimes. This research makes use of a doctrinal content analysis as well as secondary data from the law, academic journals, books, and online sources. According to the authors, unequal power relations in the workplace, anonymity, and cross-border connectedness are some of the rationales for cyberbullying, which can be expressed in a variety of ways with negative consequences for employers and employees alike. The inadequacy of the present traditional and computer-specific legislation in dealing with such crime necessitates the management of such crime.
\end{abstract}

Keywords: cyber bullying, workplace, risks, internet, Covid-19

\section{Introduction}

In the last decade, technology and social media platforms evolve, and new offences are generated and committed by utilising information and communication technology (ICT). This cycle posed problems not only to how the risks are managed but also to the traditional and cyber law governing such crime. The International Telecommunications Union (ITU) Key ICT Indicators for World Statistics stated in June 2021 that the number of persons utilising the Internet has risen to more than 4.66 billion from 3.9 billion in 2019 (ITU, 2021). Such use resulted in a wide range of activities, including the simultaneous sharing of information, images, making comments, instant messaging to friends and family, and engaging in social media, all of which could lead to the commission of numerous crimes (Hamin \& Wan Rosli, 2018). Furthermore, the proliferation of ICT usage has resulted in a new hybrid of offences, including cyber harassment and its species, cyberbullying. According to MyCERT (2021) statistics on cybercrime in Malaysia, cyber harassment incidents have been documented as early as 1998, and such 
figures have tripled in the last six years, demonstrating the frequency of the offence. CyberSecurity Malaysia asserts that not all cyber harassment incidents are recorded and that the true number of cases is larger than the publicised ones, implying that such crime is simply the tip of the iceberg and the presence of a shadow figure (MyCERT, 2021).

The global outbreak of the novel coronavirus in 2019 (COVID-19) has had a massive impact on human life. People all over the world are dealing with the medical, psychological, economic, and societal ramifications of COVID19. On March 11, 2020, the World Health Organization (WHO) declared COVID-19 as a global pandemic, with over two hundred and nineteen million people infected, including 2.1 million in Malaysia (World Health Organization [WHO], 2021). The majority of the countries around the world implemented strict quarantine procedures to prevent and eradicate the spreading of the virus. Such strict procedures include the closure of schools and non-essential businesses, imposing stay-at-home orders and curfews for all citizens which simultaneously created a new definition for working from home to the current workforce. Such profound changes had undeniably facilitated new ways of the commission of a crime such as cyberbullying. The current epidemic had increased anxiety, depression, stress, and suicide ideation.

Within the Malaysian context, research on cyberbullying at work has yet to be ventured into. Most research focuses on cyberbullying among school children and also the various impact of such crime. Wan Rosli et.al highlighted that cyberbullying often happens among school children, however, bullying at the workplace is also prevalent especially with the availability of the Internet (Wan Rosli et al., 2019).

The first section of this paper discusses the nature of cyberbullying, the various varieties of cyberbullying, and the victimisation associated with cyberbullying. The second section discusses the research methods. The third section examines employment law and cyber law, as well as the code of behaviour that governs workplace cyberbullying. The fourth section examines the responsibilities of employers as well as employees in controlling the hazards of cyberbullying in the workplace. The final section of the report delves into the research findings, which include the risk of cyberbullying in the workplace. Given the shortcomings of existing legislation dealing with such criminality, the concluding portion of the report proposes that controlling cyberbullying in the workplace should be the way ahead.

\section{Literature Review}

\section{Cyber Harassment}

Several experts feel that as technology advances and becomes more prevalent, the scope of cyber harassment, such as cyberstalking and cyberbullying, will expand (Wan Rosli, 2020). According to Stevens et al. (2021), cyber harassment is defined as an act or conduct that bothers, torments, offends, terrorises, or threatens individuals through the use of ICT such as e-mails, instant messages, and social media. He also claims that cyber harassment has all of the features of traditional harassment, but that the perpetrator extends the crime into cyberspace by using technological means to make the victim feel personally targeted. According to Choirunnisa (2021), cyber harassment includes cyberstalking and is the repetitive use of electronic communications to attack and harass a person. Basu et al. (2021) propose a broad definition of cyber harassment, including impersonation, asking third parties to attack the victim, making physical threats, and spreading false stories. Other crimes in this category include using obscene language, making insulting comments or insults, or transmitting offensive images or messages over the Internet.

\section{Nature of Cyber Bullying}

According to the existing literature on cyber harassment, cyberbullying is one of the most common types. Cyberbullying is not limited to schoolchildren; it has already spread into the workplace. According to Farley and D'Cruz (2021), workplace harassment has increasingly transitioned to cyberbullying in the current hi-tech work environment. Furthermore, it was noted that the epidemic of 
cyberbullying among adults just lately drew the attention of global researchers (Farley \& D'Cruz, 2021). Early authors, such as Hinduja and Patchin (2009), define cyberbullying as a sort of harassment that involves an intentional act that causes recurrent injury committed through the use of cell phones, computers, and other electronic devices. Harthill (2011) defines cyberbullying as "repeated, malevolent, or health-threatening maltreatment and harassment directed at someone that occurs regularly." Similarly, Abu Bakar (2013) defines cyberbullying as verbal communication that includes bullying, discrimination, and annoyance, as well as rude and demeaning comments.

According to Yusof et al. (2021), cyberbullying is an extension of traditional bullying in that it involves intent, aggression, repetition of acts and behaviours over time, and the presence of a power imbalance between the victim and the offender. Martinex-Monteagudo et al. (2019) further stated that cyberbullying will include bribes, threats of publishing sensitive information, identity theft, photo alteration, and the recording of physical assault for subsequent dissemination. In a more specific definition, Barlett (2021) contends that cyberbullying comprises anonymous, fraudulent, harassment, aggressive, unwelcome communications, unsolicited phone calls, malicious, abusive, and threatening messages, E-mail hacking, and victim attacks. He further claims that cyberbullies operate under the guise of anonymity and can reach their prey from anywhere in the world. Such harassment would cause victims to disconnect from technology, which is necessary for job and family communication. Antoniadou et al. (2019) believe that the severity of the crime may extend beyond time and geography, making it more harmful than typical bullying.

According to the existing literature, there are several types of cyberbullying. According to Paled (2019), cyberbullying includes Fraping, which is the act of accessing and impersonating the victim in order to ruin their reputation, Trolling, which is the act of insulting the victim online in order to elicit a response from the victim, and Catfishing, which is the act of stealing another person's identity to deceive the victim. It was also stated that cyberbullying will entail sexting, stalking, and possibly blackmail. According to Farley et al. (2021), cyberbullying comprises denigration or "dissing" the victim online by spreading gossip or stories about another person to harm the person's reputation, as well as outing, which is the act of disclosing another's secret or humiliating information or photographs online. He went on to say that trickery would also be considered cyberbullying because it leads the victim into disclosing intimate and embarrassing information about themselves, which is subsequently shared online without the victim's consent (Farley et al., 2021). Cyberbullying is more damaging than traditional bullying because of the allure of anonymity (Hamin \& Wan Rosli, 2018).

\section{Victimisation and Impact of Cyber Bullying}

According to the literature, the likelihood of experiencing cyberbullying victimisation is increased due to the intensity of time spent online and the lack of time and space limits, particularly in social media, which has virtually larger audiences (Karl et al., 2018). According to Karl et al., the more frequently a person accesses online social media platforms, the more likely the individual may elicit negative emotions from the digital public. According to the literature, individuals are subjected to cyberbullying because of their unique qualities such as race, class, gender, and ability. According to Barlett (2021), the grounds for targeted victimisation include a reaction to deviance, social positioning, revengeful activities, personal amusement, and even unthinking conduct.

Being involved in bullying as a young person, both as a victim and as a bully has also been proven to increase the chance of experiencing factors related to suicidal ideation, suicidal attempts, and completed suicides (Barlett, 2021; Farley et al., 2021; Bauman, Toomey, \& Walker, 2013; Campbell, Spears, Slee, Butler, \& Kift, 2012; Skapinakis et al., 2011). According to Kaluarachchi et al. (2021), any participation in bullying raises risk factors such as sadness and anxiety, which can be related to suicide ideation and/or behaviour in a wide range of kids. Victimization of cyberbullying is related to major physical and mental health conditions, which can have long-term emotional and psychological implications (Choirunnisa et al., 2021; Wan Rosli et al., 2019; Hinduja \& Patchin, 2014; Wolak, Finkelhor, Mitchell, \& Ybarra, 2008). Furthermore, cyberbullies do not receive immediate feedback for their acts, which can lead to a lack of empathy and comprehension of the victim's repercussions (Feinberg \& Robey, 2009). 


\section{Deficiency of the Legislation Governing Cyber Bullying in Malaysia}

The Employment Act 1955 and the Communication and Multimedia Act 1998 are Malaysian legislation that may apply to bullying and cyberbullying. In 2012, the Employment Act of 1955 was revised to include Part XVA, which governs sexual harassment in the workplace. The new modification to the Employment Act of 1955 addresses topics such as wage payment, overtime compensation, welfare and maternity issues, and sexual harassment against women. Despite such wide modifications, other sorts of harassment risks, such as bullying, were not addressed in the amendment.

According to Section 81A of the newly introduced Part XVA, a sexual harassment complaint under the Act includes allegations made by an employee against another employee, an employee against the employer, or an employer against an employee. According to Mallow (2013), the new amendment's application is limited because it only applies to people under a contract of service and not to those engaging in income-generating activities such as vendors, doctors, and others. Section 81B of the 1955 Act states that employers have a legal obligation to investigate any sexual harassment accusation filed within their employment. Under the 1955 Act, the company also has the authority to terminate, downgrade, suspend without pay, or refer the offender to the relevant disciplinary authorities.

Section 233 of the Criminal Misbehavior Act of 1998 may be employed to deal with internet harassment, including cyberbullying. Such a provision covers the improper use of network facilities or network services when a person initiates communication using any application service continuously and repeatedly, with or without disclosing his identity and with the intent to annoy, abuse, threaten, or harass any person at any number or electronic address. On conviction, a person who commits an offence under this section faces a fine not exceeding 50,000 ringgit or jail for a term not exceeding one year, or both. A person can also be punished a thousand ringgit for each day that the offence continues after the conviction. Despite the legal protection provided by Section 233, which may be used to prosecute perpetrators of cyberbullying, no such case has been brought before a court yet.

Aside from the Employment Act of 1955 and the Communication and Multimedia Act of 1998, the Code of Practice on the Prevention and Eradication of Sexual Harassment in the Workplace 1999 provides victims with additional safeguards. The Ministry of Human Resources established such a Code to serve as a guideline and advise to private enterprises dealing with sexual harassment in the workplace (Mallow, 2013). The Code's ultimate goal is to eliminate sexual harassment in the workplace, as well as to establish proper processes for dealing with the problem and preventing it from recurring (Mallow, 2013). As a result, the Code would serve as a reference for private organisations to develop a more extensive and comprehensive sexual harassment policy. Suriyadi Halim Omar FCJ held in the case of Mohd Ridzwan bin Abdul Razak v Asmah Binti Hj Mohd Nor [2016] MLJU 227 that the 1999 code of practice only serves as a guideline and that the code is only limited to sexual harassment and does not cover tort of harassment such as stalking under sections 2A and 4A of the Protection from Harassment Act 1997. It was also pointed out that the latest change to the Malaysian Employment Act 1955 merely imposes an obligation on employers to effectively handle sexual harassment accusations at their workplace, and that the crime of harassment remains undefined under Malaysian law.

\section{Methodology}

This study adopts a qualitative methodology using a library-based research method to critically review the literature on cyberbullying particularly on the nature and victimisation of the crime. The primary and secondary sources of data will be examined through the content analysis method. The former relates to the Employment Act 1955 and the Communications and Multimedia Act 1998 upon which a critical review will be conducted to examine the legal framework of cyberbullying in Malaysia. The latter refers to the content analysis of textbooks, journal articles, government reports, working papers, commentaries on case laws, and online databases such as Emerald, Hein Online, and Sage Publication which is done to support the primary sources of data. 


\section{Result}

\section{The Risks of Cyber Bullying in the Workplace}

Literature highlights that the new electronic workplaces are rife with a number of hazards, including traditional and cyberbullying. Zhang et. al (2021) emphasizes that the risk of bullying via Internet communications is on the rise especially during the pandemic, and organisations are becoming more aware of such issues especially since a mandatory work from home order has become a norm since the world was hit by Covid-19. Threats of workplace harassment can take many forms, including sexual harassment, racial harassment, age harassment, religious harassment, disability harassment, and sexual orientation harassment. According to Hamin and Wan Rosli (2017), the hazards of workplace harassment include prejudice, stereotyping, discrimination, sexism, and, ultimately, the abuse of authority that leads to such misconduct. A series of incidents could culminate in an offensive and hostile work environment especially online (Symons, 2021). A sequence of or cumulative behaviours may produce an intimidating environment that jeopardises an individual's integrity or dignity (Wan Rosli and Hamin, 2019; Gilani, 2014). Furthermore, if the harassment persists for a certain period of time, it will devolve into a pattern of behaviour that will eventually lead to bullying. According to Symons (2021), Escartin (2021), Mukhulo (2019), and Piotrowski (2012), online bullying is an annoyance or workplace irritant, while cyberstalking is a more hazardous type of abuse and risk. According to Kowalski and Robbins (2021), cyberbullying in the workplace takes the form of offensive emails or text messages containing jokes or inappropriate wording, changing a person's screensaver to offend or manipulate them, being mean and offensive to the victim on social media, and spreading rumours or gossip online, which can have serious consequences for coworkers.

Workplace harassment can take many forms, including discrimination, intimidation, bullying, and stalking (Farley, 2021). The hazards of harassment via ICT and social media, in particular, could take numerous forms, including drawings, words, photos, animations, and videos, with the material intended to humiliate or hurt the recipient directly or indirectly (Kowalski and Robbins, 2021). Similarly, Kalyar et al. (2020) contends that cyberbullying hazards can manifest themselves in a variety of formats, including text, drawing, photos, animations, and videos, in which the information undermines, humiliates, or injures the individual directly or indirectly. According to Zhang (2021), the risk of workplace bullying is four times greater than the risk of workplace discrimination. Kim and Choi (2021) define workplace bullying as activities such as shouting, swearing, criticising, provoking fights, threatening, making the victim feel sexually inadequate, nagging, and putting the victim down in front of colleagues. According to Alipan (2019), the risks of common workplace bullying include unreasonable targets or deadlines, repeatedly picking on the victim, concealing information, and impeding promotions.

According to the literature, there are unequal power relations and negotiating positions between the aggressors and the victims. According to Kim and Choi (2021), cyberbullying in the workplace may involve a power imbalance between the parties in which the target is unable to defend themselves, such as supervisors bullying their subordinates. Along the same lines, Gardella et al. (2019) argue that lowwage workers are more vulnerable to workplace harassment and violence and that these workers almost never seek justice against their violators.

According to the literature on workplace risks and criminality, the victims suffer significant consequences as a result of the dangers. For example, Makhulo (2019) states that cyberbullying has a considerable negative impact on workplace morale and productivity. Victims have also been reported to have experienced severe physical and psychological trauma, clinical depression, failing health, posttraumatic disorder, cardiovascular difficulties, and even chronic fatigue syndrome (Wan Rosli et al., 2020). Similarly, Paled (2019) emphasises that the expansion of social media and the Internet leads to misuse in the form of cyberbullying hazards, which may cause emotional anguish to victims in today's workplace. Career advancement, such as promotions, may also be endangered when victims take longterm or recurring breaks as a result of poor health or stress at work as a result of being cyberbullied (Symons, 2021). 
The financial and social consequences of such risks on the organisation are unavoidable. Such risks could result in institutional losses due to increased absenteeism, poor public relations, high employee turnover, and increased workplace hostility. In the United Kingdom, the hazards of cyber cyberbullying resulted in low productivity, poor performance, absence from work, resignations, harm to corporate reputation, and, in extreme situations, tribunal or court cases (UK Government Report, 2020). Similarly, Escartin (2021) contends that the hazards of cyberbullying have resulted in several incidents of unjust, constructive, and summary dismissal of employees in the workplace. A recent Productivity Commission Report (2020) done in Australia discovered that online workplace bullying is a major contributor to workplace stress, causing an increase in absenteeism and employee inefficacy.

\section{Discussion}

\section{Managing the Risks of Cyber Bullying at Work}

Because companies have a legal obligation to provide a safe working environment for their employees (Farley, 2021), they risk being held vicariously liable for any bullying that occurs in the workplace, particularly bullying committed by an employee against another employee (Kalyar et al., 2020). Hsieh et al. (2019) rightly propose that businesses implement anti-bullying and anti-discrimination policies that enable effective complaint and grievance channels of communication and processes especially when the majority of workers are online. Similarly, Loh and Snyman (2020) argue that companies play an important role in providing clear and explicit standards of behaviour required of their employees about online communication, particularly social media.

Such anti-bullying measures must be supported by ICT policies governing the use of computers, the Internet, and social media. Employers must also adopt such policies so that employers have access to their computing hardware and are aware of good workplace behaviour when using electronic devices. It would also allow for the investigation of suspected cyberbullying incidents conducted using work equipment (Karthikeyan, 2021; Peled, 2019). Organizations must also make it clear that any use of the Internet or any communication device in publishing statements on Facebook, Twitter, Instagram, personal blogs, or forums are personal opinions and do not represent the organisations' views (Farley et al., 2021; Giumetti \& Kowalski., 2019). This guideline applies during regular working hours, business travel, and any work-related social activities (Kim \& Choi, 202; Karthikeyan, 2021). Employers must also make it clear that any comments or blog posts made online by employees should not contain any indication that the owner is operating in an official role as an employee of the firm (Kabiri et al., 2021; Smith, 2019). It should be made clear that retaliation for any bullying-related allegations is not acceptable (Kabiri et al., 2021; Smith, 2019).

Employers must also educate their employees on how to avoid becoming involved in an online-induced harassment claim (Wan Rosli et al., 2019; Pastorek, Sawyer, \& Thomas, 2015). According to Gilani (2014), sensitivity and cultural competency training are crucial for all employees in addition to clear policies and anti-harassment training. Employers should consider stress management training, conflict management training, bystander training, and effective communication training between supervisors and employees when dealing with workplace harassment (Kowalski, 2021; Wan Rosli et al., 2019; Giumetti \& Kowalski, 2019).

Organizations or employers must also improve their security measures by installing new electronic surveillance systems, not only to prevent or block any attempt at cyberbullying incidents but also to monitor their employees within the physical boundaries of the workplace as well as their online activities at work (Wan Rosli et al., 2019; Taylor, 2015). Such workplace electronic monitoring should be accompanied by the implementation of a monitoring policy to monitor all electronic and communications equipment owned by the company. Such actions would indicate companies' good faith and proactive measures to prevent workplace cyberbullying (Symons, 2021; Farley \& Coyne, 2019).

Creating a workplace hotline or encouraging employees to file complaints against the aggressor is another approach for employers to assist their employees. Employers should also encourage their 
employees to directly notify the harasser of his unpleasant actions (Farley et al., 2021; Wan Rosli et al., 2019; Anasori, Bayighomog, \& Tanova, 2019). According to the US Equal Employment Opportunity Commission (2021), employees should be encouraged to warn the perpetrator that the bullying is unacceptable. Employees must also guarantee that the bullying report is filed as soon as possible to prevent the problem from escalating (US Employment Opportunity Commission, 2021).

\section{Conclusion}

Existing modern workplaces exemplify the double-edged sword of technical benefits and development enabling new office abilities on the one hand. On the other side, the same technology is spawning new hybrids of hazards and criminalities, such as harassment and its components, cyberstalking, and cyberbullying. The availability of modern technology, the Internet, new social media, anonymity, and transnational connectedness, as well as the inequality in power relations between employers and employees, have all had an impact on the prevalence of workplace cyberbullying. The consequences of such dangers on employees are incalculable, since they harm them not only physically and mentally, but also economically in terms of their career prospects. Employers face significant financial and reputational consequences as a result of this. Employers would suffer if there was a large turnover of personnel, poor public relations, increased workplace violence, and potential suits and lawsuits resulting from such bullying.

The legal framework that governs cyberbullying in Malaysia is inadequate, considering that employment legislation focuses solely on real-world sexual harassment rather than other sorts of harassment. On the other hand, the cyber legislation created for online illegalities and hazards has yet to be used by courts to punish any cyberbullying instances. In the long run, legislative change should be done to include cyberbullying in the existing statute book in order to be on par with other jurisdictions that have their specific anti-harassment laws, such as the UK and Singapore.

Because of the current legal gap, companies must use different methods to cope with such criminality and risks especially with the change of working environment during the pandemic. In the current atmosphere of legal uncertainty, managing workplace bullying in the real world and cyberspace may be the best and most practical technique for organisations to use. Indeed, they must implement a comprehensive mechanism to combat workplace bullying, ranging from implementing organisational norms involving relevant policies on ICT usage and anti-bullying to awareness and educational programmes and training, to implementing electronic surveillance systems and monitoring policies. Perhaps employers' associations and the government could collaborate to develop precise standards to govern cyber harassment in the workplace, similar to the 1999 Guidelines on Sexual Harassment.

\section{Acknowledgement}

This work was supported by research grant FRGS/1/2019/SSI10/UITM/02/2 by the Research Management Centre, UiTM Shah Alam, Selangor, Malaysia.

\section{References}

Alipan, A., Skues, J.L., Theiler, S. et al. (2019). International Journal of Bullying Prevention. https://doi.org/10.1007/s42380-019-00018-6

Anasori, E., Bayighomog, S. W., \& Tanova, C. (2019). Workplace bullying, psychological distress, resilience, mindfulness, and emotional exhaustion. The Service Industries Journal, 1-25.

Barlett, C. P., Simmers, M. M., Roth, B., \& Gentile, D. (2021). Comparing cyberbullying prevalence and process before and during the COVID-19 pandemic. The Journal of Social Psychology, 111 . 
Basu, P., Singha Roy, T., Tiwari, S., \& Mehta, S. (2021, September). CyberPolice: Classification of Cyber Sexual Harassment. In EPIA Conference on Artificial Intelligence (pp. 701-714). Springer, Cham.

Choirunnisa, S. (2021). Legal Protection Against Women Victims of Sexual Harassment Through Social Media (Cyberporn). The Indonesian Journal of International Clinical Legal Education, 3(3), 367-380.

Deo, S.S. (2016). The criminal law (amendment) act 2013: legislative remedies for online harassment and cyberstalking in India. Retrieved from http://papers.ssrn.com/sol3/papers.cfm?abstract_id=2712052.

Escartín, J., Vranjes, I., Baillien, E., \& Notelaers, G. (2021). Workplace bullying and cyberbullying scales: An overview. Concepts, Approaches and Methods, 325-368.

Farley, S., Coyne, I., \& D'Cruz, P. (2021). Cyberbullying at work: Understanding the influence of technology. Concepts, Approaches and Methods, 233-263.

Gardella, J.H., Fisher, B.W., Teurbe-Tolon, A.R. et al. (2019). International Journal of Bullying Prevention https://doi.org/10.1007/s42380-019-00017-7

Cavico, F. J., Mujtaba, B. J. (2014). Harassment at the workplace: a practical review of the laws in the United Kingdom and the United States of America. Public Organization Review, 14, 1-18.

Gilani, S. R. S., Cavico, F. J., Mujtaba, B. J. (2014). Harassment at the workplace: a practical review of the laws in the United Kingdom and the United States of America. Public Organization Review, 14, 1-18.

Giumetti, G. W., \& Kowalski, R. M. (Eds.). (2019). Cyberbullying in Schools, Workplaces, and Romantic Relationships: The Many Lenses and Perspectives of Electronic Mistreatment. Routledge.

Hamin Z and Wan Rosli, WR (2018). Cloaked by Cyber Space: A Legal Response to the Risks of Cyber Stalking in Malaysia. International Journal of Cyber Criminology, 12(1), 316-332.

Hsieh, Y., Wang, H., Ma, S. (2019). The mediating role of self-efficacy in the relationship between workplace bullying, mental health, and an intention to leave among nurses in Taiwan. International Journal of Occupational Medicine and Environmental Health, 32(2), 245254. https://doi.org/10.13075/ijomeh.1896.01322

Kabiri, S., Choi, J., Kruis, N., Shadmanfaat, S. M., \& Lee, J. (2021). Social Concern as a Means of Understanding the Risk of Workplace Deviance. Deviant Behavior, 1-20.

Kaluarachchi, C., Sedera, D., \& Warren, M. (2021). An Investigative Model of Adult Cyberbullying: A Court Case Analysis.

Kalyar, M. N., Saeed, M., Usta, A., \& Shafique, I. (2020). Workplace cyberbullying and creativity: examining the roles of psychological distress and psychological capital. Management Research Review.

Karthikeyan, C. (2021). Conceptualizing Causative Factors of Workplace Cyberbullying on Working Women. In Research Anthology on Changing Dynamics of Diversity and Safety in the Workforce (pp. 164-184). IGI Global.

Kim, Y. J., \& Choi, J. S. (2021). Individual and organizational factors influencing workplace cyberbullying of nurses: A cross-sectional study. Nursing \& Health Sciences.

Kowalski, R. M., \& Robbins, C. E. (2021). The Meaning, Prevalence, and Outcomes of Cyberbullying in the Workplace. In Handbook of Research on Cyberbullying and Online Harassment in the Workplace (pp. 1-22). IGI Global.

Loh, J., \& Snyman, R. (2020). The tangled web: consequences of workplace cyberbullying in adult male and female employees. Gender in Management: An International Journal.

MyCERT Incident Statistics retrieved from www.mycert.org.my

Olweus, D., Limber, S.P. \& Breivik, K. (2019). Addressing Specific Forms of Bullying: A LargeScale Evaluation of the Olweus Bullying Prevention Program. International Journal of Bullying Prevention, 1, 70. https://doi.org/10.1007/s42380-019-00009-7

Peled Y. (2019). Cyberbullying and its influence on academic, social, and emotional development of undergraduate students. Heliyon, 5(3), e01393. doi:10.1016/j.heliyon.2019.e01393

Productivity Commission. (2019). Workplace Relations Framework. Productivity Commission Inquiry Report, 1(76).

Smith, P. K. (2019). Research on Cyberbullying: Strengths and Limitations. In Narratives in Research and Interventions on Cyberbullying among Young People (pp. 9-27). Springer, Cham. 
Stevens, F., Nurse, J. R., \& Arief, B. (2021). Cyberstalking, cyber harassment, and adult mental health: A systematic review. Cyberpsychology, Behavior, and Social Networking, 24(6), 367376.

Symons, M. M., Di Carlo, H., \& Caboral-Stevens, M. (2021, January). Workplace cyberbullying exposed: A concept analysis. In Nursing forum, 56(1), 141-150.

U.S. Equal Employment Opportunity Commission. (2020). Harassment. Retrieved from https://www.eeoc.gov/laws/types/harassment.cfm.

UK Government. (2020). Workplace Bullying and Harassment. Retrieved from www.gov.uk/workplace-bullying-and-harassment.

Wan Rosli, WR, Kamaruddin, S. (2020). When Love Is Jeopardized: Governing Online Love Scams In Malaysia. International Journal of Advanced Science and Technology, 29(6), 391-397.

Yusof Nur Amalina, Y., Chinniah, M., Aini Othman, A., Shamala, P., \& Hussein Zolait, A. (2021). A Systematic Literature Review on Characteristics of Cyberbullying. International Journal of Computing and Digital System.

Zhang, Z., Wang, H., Zhang, L., \& Zheng, J. (2021). Workplace cyberbullying and interpersonal deviance: roles of depletion and perceived supervisor support. Asia Pacific Journal of Human Resources. 